BMJ Paediatrics Open

\title{
Working together better for mental health in children and young people during a pandemic: experiences from North Central London during the first wave of COVID-19
}

Monika Gorny (D) , ${ }^{1}$ Sarah Blackstock, ${ }^{2}$ Arun Bhaskaran, ${ }^{2}$ Imogen Layther, ${ }^{3}$ Mimoza Qoba, ${ }^{1,4}$ Carly Vassar, ${ }^{3}$ Jacob Ellis, ${ }^{2}$ Joanna Begent, ${ }^{2}$ John Forrester, ${ }^{3}$ Jon Goldin, ${ }^{3}$ Zoe Hallet, ${ }^{3}$ Tina Read, ${ }^{5}$ Sally Hodges, ${ }^{6}$ Michael Groszmann, ${ }^{2}$ Lee Duncan Hudson ${ }^{3}$

To cite: Gorny M, Blackstock S, Bhaskaran A, et al. Working together better for mental health in children and young people during a pandemic: experiences from North Central London during the first wave of COVID-19. BMJ Paediatrics Open 2021;5:e001116. doi:10.1136/ bmjpo-2021-001116

Received 1 April 2021 Accepted 19 August 2021

\section{Check for updates}

C Author(s) (or their employer(s)) 2021. Re-use permitted under CC BY-NC. No commercial re-use. See rights and permissions. Published by BMJ.

${ }^{1}$ Royal Free Hospital, London, UK ${ }^{2}$ University College London Hospital NHS Trust, London, UK ${ }^{3}$ Great Ormond Street Hospital for Children, London, UK

${ }^{4}$ Royal Free Hospital NHS Trust, London, UK

${ }^{5}$ Barnet Enfield and Haringey CAMHS, Enfield, UK

${ }^{6}$ Tavistock and Portman NHS Trust, London, UK

Correspondence to Dr Monika Gorny; monika. gorny2@nhs.net

\section{ABSTRACT}

Direct risk from infection from COVID-19 for children and young people (CYP) is low, but impact on services, education and mental health (so-called collateral damage) appears to have been more significant. In North Central London (NCL) during the first wave of the pandemic, in response to the needs and demands for adults with COVID-19, general paediatric wards in acute hospitals and some paediatric emergency departments were closed. Paediatric mental health services in NCL mental health services were reconfigured. Here we describe process and lessons learnt from a collaboration between physical and mental health services to provide care for CYP presenting in mental health crisis. Two new 'hubs' were created to coordinate crisis presentations in the region and to link community mental health teams with emergency departments. All CYP requiring a paediatric admission in the first wave were diverted to Great Ormond Street Hospital, a specialist children's hospital in NCL, and a new ward for CYP mental health crisis admissions was created. This brought together a multidisciplinary team of mental health and physical health professionals. The most common reason for admission to the ward was following a suicide attempt $(n=17,43 \%)$. Patients were of higher acute mental health complexity than usually admitted to the hospital, with some CYP needing an extended period of assessment. In this review, we describe the challenges and key lessons learnt for the development of this new ward setting that involved such factors as leadership, training and also new governance processes. We also report some personal perspectives from the professionals involved. Our review provides perspective and experience that can inform how CYP with mental health admissions can be managed in paediatric medical settings.

\section{INTRODUCTION}

At the time of writing, the SARS-CoV-2 pandemic, or COVID-19, has caused 192284207 infections and 4136518 deaths globally. ${ }^{1}$ The first case of SARS-CoV-2
Key messages

During the first wave of COVID-19 physical and mental health services collaborated within NCL for CYP mental health crisis presentations across community and hospital care.

- All paediatric admissions were diverted to Great Ormond Street Hospital where a new ward for mental health crises was created.

- Patients of high acute mental health complexity were admitted to Great Ormond Street Hospitalleadership, training and development of governance and risk mitigation were important.

- Mental health crisis admissions are increasingly common and will continue to be common to paediatric medical settings so training and service development is necessary.

infection emerged in the UK in early 2020, with the first recorded death in early March. ${ }^{2}$ Direct risk to children and young people (CYP) has however thankfully been low. ${ }^{3}$ Despite this, the indirect effects of the pandemic and associated societal responses have been significant for CYP. Sometimes described as 'collateral damage', ${ }^{4}$ the pandemic has had consequences for the provision of health services ${ }^{4}$ and access to education for CYP. ${ }^{4-6}$ Of particular concern are the implications for the mental health and well-being of CYP. ${ }^{7}$ Cross-sectional data from China from early in the pandemic reported higher levels of anxiety in CYP compared with what might be expected using data prior to the pandemic. ${ }^{8}$ A longitudinal study of adolescent mental health, combining data sets from 12 countries (including North America, South America and Europe) reported an increase 
in depressive symptoms through the pandemic, especially in those subjected to lockdown but stable levels of anxiety. ${ }^{9}$ In the UK, a 2017 nationally representative data in England found that around 10\% of CYP had at least one mental health disorder, ${ }^{10}$ yet when this survey was repeated in 2020, prevalence was found to have increased to $16 \% .{ }^{11}$ There has also been a rise in the number of CYP presenting with eating disorders in a number of countries. ${ }^{12-14}$ It should be highlighted that although evidence points to increased rates of mental health problems, not all children were affected, and there is evidence that some children thrived and reported life to be better. ${ }^{15}$

There are likely to be a range of reasons as to why mental health has been affected during the pandemic for some CYP. Many countries instigated periods of 'lockdown', which included the closure of schools. ${ }^{16}$ Lockdown inevitably meant that CYP were unable to see friends and extended family, and this could have left to feelings of isolation and loneliness, both of which were found to be associated with increased rates of depression in a recent systematic review. ${ }^{17}$ Stay-at-home enforcement may also have in particular exacerbated CYP suffering from eating disorders in exacerbating cognitions and behaviours through altering routines and worsening anxiety. ${ }^{18}$ CYP mental health could have also been impacted by household stresses such as income and food security, factors known to be associated with the psychological well-being of CYP. ${ }^{19}$ Another important potential factor for the mental health of CYP is access to healthcare. Though emergency departments and hospitals remained open to admissions, some services were reconfigured in anticipation of greater demand for patients with COVID-19, and also working styles were altered to respond to the lockdown and risk of infection spread (eg, use of telemedicine).$^{20}$ Bertz $e t a l^{21}$ found that, despite offering face-to-face appointments when necessary in the Child and Adolescent Mental Health Services (CAMHS) community clinics, few CYP attended in person. A significant proportion of young people have also reported disruption to their mental health services. ${ }^{22}$ Published perspectives on emergency responses to sudden environmental changes such as natural disasters have identified a need for attention to be paid to mitigation of the impact on mental health through responses and adaptation in healthcare deliverers. ${ }^{23-25}$ Yet, there is a paucity of published literature of examples of actual service developments as responses, including for mental health crises in CYP during infectious pandemics. Here we describe our experiences of collaborative working within North Central London (NCL) to deliver care for CYP requiring mental health crisis support in response to the first wave of COVID-19.

\section{NCL and the mental health network changes during the first wave of the pandemic}

NCL is a geographical region comprising the five boroughs of Barnet, Enfield, Haringey, Camden and Islington, with a population of 1.5 million people, of which around $20 \%$ are CYP. Four of the five boroughs have a greater proportion of CYP living in poverty than the London and national averages. ${ }^{26}$ The region has six hospitals that provide acute medical services for CYP: University College London Hospital, Barnet Hospital, Royal Free Hospital, North Middlesex Hospital, Whittington Hospital and Great Ormond Street Hospital $(\mathrm{GOSH})$, which also provides specialist paediatric care for the four mental health trusts. Prepandemic, the model for management of CYP presenting in mental health crisis across NCL consisted of professional liaison between the emergency departments across the region and outreach and community teams.

In March 2020, in response to the pandemic, there was a major reorganisation of NCL child and adolescent health services. The paediatric emergency departments at University College London Hospital and Barnet Hospital closed, and the paediatric inpatient units at University College London Hospital, Royal Free Hospital, Barnet Hospital and North Middlesex Hospital were also closed to create space for treatment of adult patients with COVID-19 presentations. Paediatric patients requiring admission were transferred to GOSH, a specialist paediatric hospital in NCL. GOSH does not normally admit patients acutely via the emergency department; however, pathways were reconfigured (as shown in figure 1, describing the new CYP Mental Health pathway), and new general paediatric wards were opened using medical and nursing teams from within the hospital and across the region. Two crisis hubs were created: one in the South and one in the North of the region. The purpose of the hubs was to assess mental crisis health presentations directly, redirecting patients from emergency departments where possible. Some of the out of hours team clinicians, whose working hours have been extended to 00:00 7days a week, as well as some members of the hospital CAMHS liaison teams, were redeployed to the South, North Hubs, as well as GOSH's mental health ward. ${ }^{27}$ Twice daily (am and pm) professional 'huddles' were scheduled. In these 'huddles', teams based in ED, the community and the hubs could communicate via telephone or video calls and share information about current and potential emerging crises. They allowed open communication between teams and thoughtful, multidisciplinary management of patients in mental health crisis. Community child and adolescent mental health teams also stepped up care and contact for existing CYP patients under their care in an attempt to minimise escalation into crisis. Data regarding total monthly numbers of out of hours CYP presenting with mental health crises between January (before the pandemic) and May within NCL are presented in figure 2. Prior to the changes across NCL described, the out of hours crises team were based in emergency departments in hospitals, whereas during the pandemic, the new crisis hubs were outside of emergency departments and provided out of hours crisis provision away from the emergency departments. As 


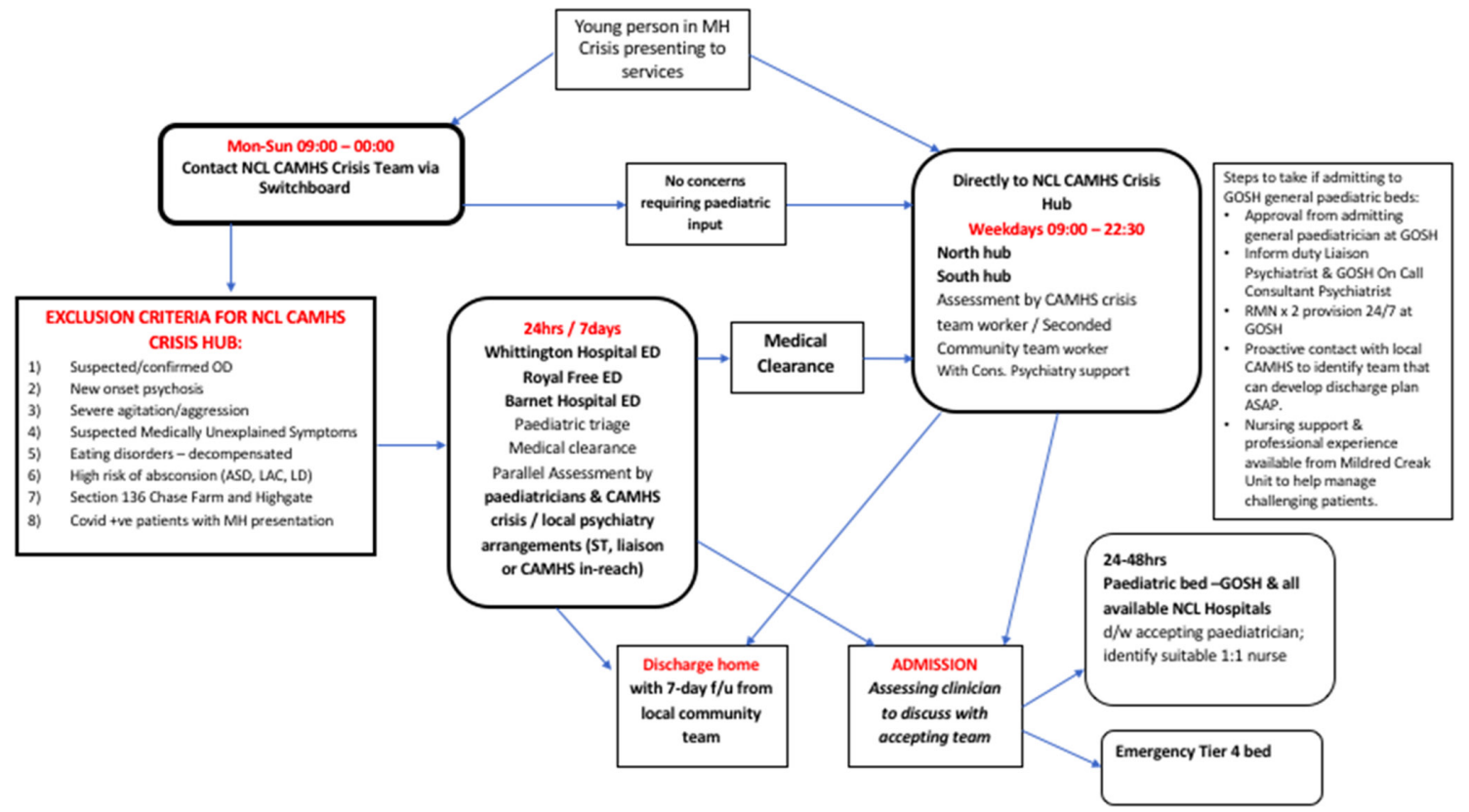

Figure 1 North Central London reconfigured CYP mental health pathway: March 2020. ASD, Autism Spectrum Disorder; CAMHS, Child and Adolescent Mental Health Services; CYP, children and young people; ED, Emergency Department; f/u, follow up; GOSH, Great Ormond Street Hospital; LAC, Looked After Children; MH, mental health; OD, overdose; ST, Senior Trainee.

figure 2 shows, total numbers of presentations increased, but the formation of the hubs appear to have reduced presentations to EDs crisis teams.

\section{Mental health crisis admissions to GOSH}

As general paediatric admissions were concentrated at GOSH, it quickly became apparent that a significant proportion were mental health crisis admissions, as well as their physical consequences (eg, self-inflicted wounds and overdoses). Both the number of admissions and the usual environment and skill base at GOSH meant that a new model of care was required. This was implemented

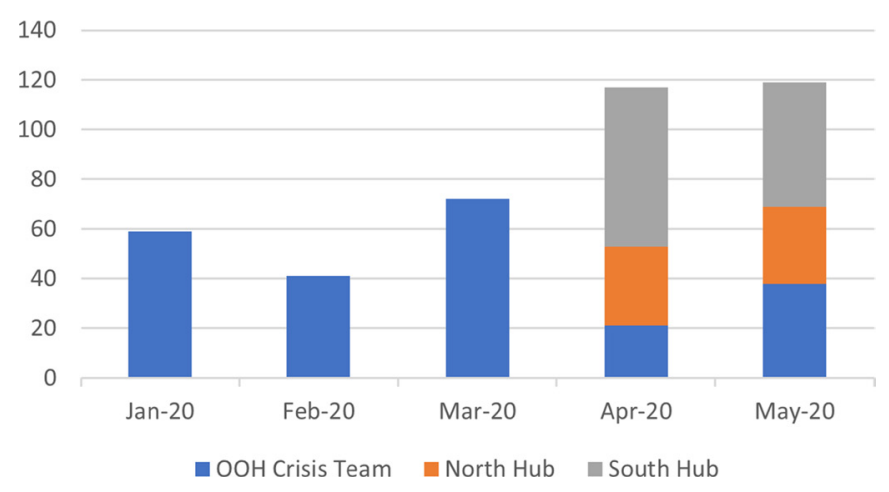

Figure 2 Out of hours $(\mathrm{OOH})$ CYP mental health presentations between January and May 2020. Prior to the pandemic (January-March) $\mathrm{OOH}$ crisis presentations were to teams in emergency departments (blue bar). During April-May, crisis presentations were also taken by the hubs (orange $=$ north and grey=south) which, despite overall increases in total numbers of our of hours presentations, took the majority of out of hours presentations. CYP, children and young people. rapidly and with collaboration between services. A new ward within the hospital was sourced and developed specifically for mental health crisis admissions. A summary of the characteristics of the admissions during the first wave is shown in table 1 . There were 39 mental health admissions between 1 March and 31 May 2020. Most young people admitted were over 12 years, but some were as young as 9 years. The most common reason for admission was following suicide attempt $(\mathrm{n}=17,44 \%)$. Some CYP needed repeat admission, and some an extended period of assessment (with the longest length of stay being 13 days), and 11 (29\%) were transferred to a tier 4 unit. The rest were discharged under the care of specialist crisis community services. Admissions were joint between paediatrics and mental health. The ward was staffed by both paediatric and registered mental health nurses from within and outside the hospital. Child and Adolescent Psychiatry consultants with a special interest in psychiatry liaison were redeployed from University College London Hospital, along with middle grades from the region, who worked alongside GOSH psychiatry staff. Existing social work teams and pathways were utilised. A morning multidisciplinary 'huddle' around mental health patients admitted occurred daily, with a focus on care and planning for the admission, as well as expected new admissions. As a significant proportion of patients admitted in mental health crisis also had complex physical health problems (eg, wounds, starvation and, in some cases, medically unexplained symptoms), coworking between mental and physical health teams through multidisciplinary working proved very helpful in providing holistic medical care for patients (including rapid access to 
Table 1 Summary of mental health crisis admissions to Great Ormond Street Hospital during the first wave of COVID-19 between 1 March and 31 May 2020.

\begin{tabular}{ll}
\hline Duration of admission & Days \\
\hline Mean length of stay & 3.9 \\
\hline SD for average length of stay & 3.5 \\
Longest length of stay & 13 \\
\hline Shortest stay & 0 \\
\hline Admission characteristics & $\mathrm{n}$ \\
\hline Number of patients & 36 \\
\hline Total number of admissions & 39 \\
\hline Number of readmissions & 3 \\
\hline Mean age (years) & 15 \\
SD for age & 2 \\
Admission diagnoses & $\mathrm{n}(\%)$
\end{tabular}

Self harm and suicidal behaviour (DSH/suicidal 17 (44) ideation)

\begin{tabular}{|c|c|}
\hline Affective symptoms: anxiety and low mood & $6(15)$ \\
\hline $\begin{array}{l}\text { Psychotic presentations: psychotic, hypomania } \\
\text { and mania }\end{array}$ & $1(3)$ \\
\hline Behavioural issues: agitation/withdrawal/mutism & $4(10)$ \\
\hline Substance misuse & 0 \\
\hline Somatisation/functional presentations & $3(8)$ \\
\hline Social issues/out of parental control & $1(3)$ \\
\hline Disordered eating & $5(13)$ \\
\hline No information & $2(5)$ \\
\hline Mental health act admissions status & $\mathrm{n}(\%)$ \\
\hline Number of voluntary admissions & $26(67)$ \\
\hline Number of section 2 & $6(15)$ \\
\hline Number of section 5.2 & $5(13)$ \\
\hline Number of section 3 & $2(5)$ \\
\hline Nursing ratios & n (\%) \\
\hline Number of patients under general observation & $5(13)$ \\
\hline Number of patients under 1 to 1 supervision & $22(56)$ \\
\hline Number of patients under 2 to 1 supervision & $9(23)$ \\
\hline Number of patients under 3 to 1 supervision & $3(8)$ \\
\hline Ward intervention & $\mathrm{n}$ \\
\hline Number of episodes of sedation & 4 \\
\hline Number of episodes of restraint & 9 \\
\hline Discharge location & $\mathrm{n}$ \\
\hline Number of discharges to home/family member & 22 \\
\hline Number of discharges to tier 4 & 11 \\
\hline Discharges to social care & 3 \\
\hline Discharges to specialist ASD service & 1 \\
\hline
\end{tabular}

ASD, Autism Spectrum Disorder; DSH, Deliberate Self Harm.

other medical specialities such as neurology, surgery and diagnostics). The multidisciplinary approach was also particularly important in the context of lockdown given the widespread general concerns about safeguarding and vulnerability during the pandemic.

These described changes at Great Ormond Street happened over the space of a few days, requiring flexibility and resilience from staff members involved. A particular challenge was that the staff at Great Ormond Street were not used to the kinds of admissions they were now working with. The national healthcare regulator, the Care Quality Commission registration status of GOSH for detention under the Mental Health Act, had to be changed to facilitate adaptations from usual practice, including detaining patients under the act. The ward environment needed to be changed to adapt to patients with complex mental health needs, for example, physical bed locations and removal of potential ligature risk points. For governance, a visit to the ward was organised by GOSH of leadership representatives from the local mental health trusts who provided a review of the ward set up and protocols as well as recommendations. This new style of working was understandably challenging for some staff, but bringing together skills from other centres helped support the work.

When asked for their reflections, team members at GOSH, who were directly involved in the NCL response to COVID-19, emphasised the importance of collaborative working, in order for the new system to work smoothly. They spoke about feeling proud to be able to deliver high-quality, holistic medical and nursing care, a tailored treatment package for every patient, with close liaison with community teams. It became clear that a shared goal and strong will to develop a well-functioning system aided the impossibly quick development of a working service. Team members also spoke fondly of the daily handover meetings which, with a dose of humour and shared experiences, provided a sense of comradery between the collaborating sites.

\section{Key lessons and opportunities for the future}

The sudden changes to NCL services and the unique integration of paediatric and mental health services on one ward in a specialist paediatric hospital had a number of key benefits, as well as multiple challenges. It has been recognised for some time that inpatient paediatric hospital settings have become increasingly used for mental health crises, with the Royal College of Paediatrics and Child Health providing a position statement on the role of paediatricians in mental health. ${ }^{28}$ However, this is often beset with problems. This can go wrong from the beginning, with no bed at all for such CYP and long waits in the emergency department. Paediatric wards are usually not designed for the care of CYP with mental health crises. They can sometimes be challenging environments for such CYP to be cared for, for example, the age case-mix environment (eg, much younger patients such as infants) and physical aspects of a ward, such as ligature risk can present problems. Staff who work on paediatric wards may not have the training for managing CYP with mental health crises, and specialist registered 
mental health nurses might be unavailable or, when they are brought into the ward, are not part of a usual team. Admissions can therefore be complex and challenging for CYP, families and the teams delivering the care. That said, at in the context of crisis, within existing systems, it is often the only place for them go to. Our experience of the establishment of a specific ward for CYP in mental health crisis with colocation of paediatric medical and mental health teams was similar and started from this position. However, with leadership and partnership, it developed to improve care. We feel that this provides useful lessons for mental health crisis management in more traditional paediatric physical health settings.

Having child and adolescent psychiatry and specialist mental health nurses located on site allowed for leadership and consistent liaison between the teams. Coworking and a strong multidisciplinary approach helped provide a holistic medical management. This was particularly important because of lockdown. There was also anxiety expressed by some existing GOSH medical staff about managing agitation/aggression on the ward and in particular self-introspection that this was related to lack of experience in dealing with challenging mental health presentations. This made education, mentoring and coworking pivotal to support and promoting the wellbeing of staff and mitigating risk. Medical teams working alongside mental health teams, as mentioned previously, also offered efficient availability of multiple paediatric specialities and investigations (eg, imaging) but moreover allowed for integrated mental and physical care, which proved valuable where CYP had comorbidities or where there was a range of mental and physical health differentials for presentations.

Beyond admissions to the ward, the development of care pathways and nodes of communication was felt to improve care. Regular handovers within GOSH and NCL hubs allowed the whole network to be aware of known patients and to track and plan around risk. The role of the North and South NCL hubs was communicated to primary care teams, community mental health teams and other secondary health services, thus ensuring that the new crisis pathways worked more efficiently. Despite that, at times of high demand, high pressure of transport and beds sometimes meant that CYP in crisis were held up at presentation location, often meaning waiting in $\mathrm{ED}$, waiting for local paediatric teams to develop overflow capacity. Furthermore, despite the efforts to contain crises via the hubs, many patients still presented to the EDs within NCL.

There are likely to be many knock-on effects from the pandemic, some good and some bad. It is our hope that positive, innovative solutions can develop for the care of CYP with mental health disorders in our region and further afield, from the opportunities and experiences that have come out of COVID-19. The ability to cut through red tape and cowork during the first wave has opened up new relationships and led to thinking about models of care for the future in a joined-up way. After the first wave, paediatric and mental health admissions at GOSH ceased with care returning to original sites, though in reconfigured format. The hub structure for crisis care has however largely been maintained but with mental health crisis admissions focused at nominated general paediatric wards in two locations in NCL. Regionally, there is interest in developing locations for brief paediatric admission that are more prepared and specifically designed to cater for such admissions, based on the lessons from admissions to GOSH and more broadly within NCL during the pandemic. There is limited evidence in the current literature relating to alternative mental health crisis measures to avoid admissions, such as family-based emergency single-session interventions and community setting interventions, which include those carried out at home or in a hospital clinic. ${ }^{29}{ }^{30}$ Adult mental health services have developed in some regions to provide an alternative to a hospital admission (either medical or mental health) in a form of a crisis house. Such models can allow for 'cooling off' time and for arrangements and care to be organised in the community avoiding a longer term mental health admission. The literature evidence for this approach is however sparse, with one study reporting a positive impact on quality of life and a reduction in homelessness following an adult crisis house admission. ${ }^{31}$ Such locations would need multistakeholder involvement including CYP and their families, and sustainability would require funding and also to fit alongside existing pathways for mental health. There is very little evidence on the role of paediatric wards for the care of mental health crises, and given that this is likely to be the current trend in the UK for some time, this calls for further research into this area. Moreover, there is a need for paediatric teams to be supported in upskilling in this area of work, and this should be a focus for education and training. ${ }^{32}$ This has been highlighted in the Royal College of Paediatric's 2040 Report and is a focus of the Royal College of Paediatric's Paediatrician of the Future document. Successful examples of colearning include 'Thinking together' a joint learning programme for mental health and paediatric trainees. ${ }^{334}$

In conclusion, despite the pressure of a global crisis due to the COVID-19 pandemic, we found new ways to develop care for CYP with mental health crises in a more joined up way. We have presented our experiences and lessons learnt. We would argue that learning from these experiences is important to further ensure that moving forward, opportunities to develop care for CYP should fit around the needs of CYP and not, as is far too often the case, the needs of CYP having to fit around their available care.

Acknowledgements We would like to acknowledge the children, young people and families that it was our privilege to care for through COVID-19 and all our many colleagues in health and social care across North Central London. We would like to acknowledge and thank Great Ormond Street Hospital (GOSH) Charity for the grant allowing data collection and open-access.

Contributors LDH, MG, SB and AB conceived the piece. MG, SB and LDH led the write up. Data identification was supported by MG, SB, AB, CV, IL and SH. 
MG, SB and LDH worked on the first draft, and all authors contributed to the final manuscript and were involved with the clinical work and topic discussed. All authors are involved in revising the contents of the manuscript and take responsibility for its content.

Funding This work was supported by Great Ormond Street Hospital Charity grant number VC0321.

Competing interests None declared.

Patient and public involvement Patients and/or the public were not involved in the design, or conduct, or reporting, or dissemination plans of this research.

Patient consent for publication Not required.

Provenance and peer review Not commissioned; externally peer reviewed.

Data availability statement Data are available on reasonable request.

Open access This is an open access article distributed in accordance with the Creative Commons Attribution Non Commercial (CC BY-NC 4.0) license, which permits others to distribute, remix, adapt, build upon this work non-commercially, and license their derivative works on different terms, provided the original work is properly cited, appropriate credit is given, any changes made indicated, and the use is non-commercial. See: http://creativecommons.org/licenses/by-nc/4.0/.

ORCID iD

Monika Gorny http://orcid.org/0000-0001-6715-7860

\section{REFERENCES}

1 World Health Organisation. Who coronavirus disease (COVID-19) Dashboard, 2021. Available: https://covid19.who.int/

2 Mahase E. Covid-19: UK records first death, as world's cases exceed 100000. BMJ 2020;368:m943.

3 Brodin P. Why is COVID-19 so mild in children? Acta Paediatr 2020;109:1082-3.

4 Crawley E, Loades M, Feder G, et al. Wider collateral damage to children in the UK because of the social distancing measures designed to reduce the impact of COVID-19 in adults. BMJ Paediatr Open 2020;4:e000701.

5 Lynn RM, Avis JL, Lenton S, et al. Delayed access to care and late presentations in children during the COVID-19 pandemic: a snapshot survey of 4075 paediatricians in the UK and ireland. Arch Dis Child 2021;106:e8.

6 Scottish Government. Report from the Covid-19 Advisory SubGroup on Education and Children's Issues: Summary of the Evidence on Children, Schools, Early Learning and Childcare Settings and Transmission from Covid-19, 2020. Available: https://www.gov.scot/binaries/content/documents/govscot/ publications/research-and-analysis/2020/11/coronavirus-covid19-evidence-on-children-schools-early-learning-and-childcaresettings-and-transmission-from-covid-19-summary-report/ documents/advisory-sub-group-on-education-and-childrensissues-summary-report-of-the-evidence-on-children-schools-earlylearning-and-childcare-settings-and-transmission-from-covid-19/ advisory-sub-group-on-education-and-childrens-issues-summaryreport-of-the-evidence-on-children-schools-early-learning-andchildcare-settings-and-transmission-from-covid-19/govscot\% 3Adocument/SUMMARY\%2BOF\%2BTHE\%2BEVIDENCE\% 2BON\%2BCHILDREN\%2BSCHOOLS\%2BEARLY\%2BLEARNING\% 2BAND\%2BCHILDCARE\%2BSETTINGS $\% 2 B A N D \%$ 2BTRANSMISSION\%2BFROM\%2BCOVID-19\%2B\%2528002\% 2529.pdf [Accessed 18 Nov 2020].

7 Singh S, Roy D, Sinha K, et al. Impact of COVID-19 and lockdown on mental health of children and adolescents: a narrative review with recommendations. Psychiatry Res 2020;293:113429.

8 Zhou S-J, Zhang L-G, Wang L-L, et al. Prevalence and sociodemographic correlates of psychological health problems in Chinese adolescents during the outbreak of COVID-19. Eur Child Adolesc Psychiatry 2020;29:749-58.

9 Barendse M, Flannery J, Cavanagh C. Longitudinal change in adolescent depression and anxiety symptoms from before to during the COVID-19 pandemic: a collaborative of 12 samples from 3 countries, 2021. Available: https://psyarxiv.com/hn7us/

10 NHS. Digital, Mental Health of Children and Young People in England, 2017 [PAS], 2018. Available: https://digital.nhs.uk/dataand-information/publications/statistical/mental-health-of-childrenand-young-people-in-england/2017/2017\#key-facts
11 NHS. Digital, mental health of children and young people in England, 2020: wave 1 follow up to the 2017 survey, 2020. Available: https:// digital.nhs.uk/data-and-information/publications/statistical/mentalhealth-of-children-and-young-people-in-england/2020-wave-1follow-up

12 Solmi F, Downs JL, Nicholls DE. COVID-19 and eating disorders in young people. Lancet Child Adolesc Health 2021;5:316-8.

13 Haripersad YV, Kannegiesser-Bailey M, Morton K, et al. Outbreak of anorexia nervosa admissions during the COVID-19 pandemic. Arch Dis Child 2021;106:e15

14 Spettigue W, Obeid N, Erbach M, et al. The impact of COVID-19 on adolescents with eating disorders: a cohort study. J Eat Disord 2021;9:1-8

15 Ford T, John A, Gunnell D. Mental health of children and young people during pandemic. BMJ 2021;372:n614.

16 Walker P, Adams S. Coronavirus UK: schools, colleges and nurseries to close the guardian., 2020. Available: https://www.theguardian. com/world/2020/mar/18/coronavirus-school-colleges-nurseriesengland-close-uk-friday [Accessed 18 Mar 2020].

17 Loades ME, Chatburn E, Higson-Sweeney N, et al. Rapid systematic review: the impact of social isolation and loneliness on the mental health of children and adolescents in the context of COVID-19. J Am Acad Child Adolesc Psychiatry 2020;59:1218-39.

18 McCombie C, Austin A, Dalton B, et al. "Now It's Just Old Habits and Misery"-Understanding the Impact of the Covid-19 Pandemic on People With Current or Life-Time Eating Disorders: A Qualitative Study. Front Psychiatry 2020;11:1140.

19 Melchior M, Chastang J-F, Falissard B, et al. Food Insecurity and Children's Mental Health: A Prospective Birth Cohort Study. PLoS One 2012; $7:$ e52615

20 Mueller B. Telemedicine arrives in the UK "10 Years of Change in One Week". The New York Times 2020.

21 Bertz S, Olatoye O, O'Hanrahan S, et al. Preliminary reflections of CAMHS in COVID-19 lockdown. Ir J Psychol Med 2020;37:162-3.

22 Crosby L, McCloud T, Hudson L. Disruptions experienced by young people aged 16-24 during first months of the Covid-19 lockdown, 2020. Available: https://www.ucl.ac.uk/child-health/sites/child health/files/ppp-youcope-briefing-disruptions_2020-06-23.pdf

23 White RE. Principles and practice of soil science: the soil as a natural resource. John Wiley \& Sons 2013.

24 Raviola G, Severe J, Therosme T, et al. The 2010 Haiti earthquake response. Psychiatr Clin North Am 2013;36:431-50.

25 Hasan MT, Adhikary G, Mahmood S. Exploring mental health needs and services among affected population in a cyclone affected area in costal Bangladesh: a qualitative case study. Int J Ment Health Syst 2020;14:1-9.

26 North Central London. Sustainability and transformation Plan- case for change, 2016. Available: https://www.candi.nhs.uk/sites/default/ files/Documents/160914\%20NCL\%20case\%20for\%20change\% 20September\%202016.pdf

27 Commissioner Children's. Inpatient mental health wards during covid-19. Briefing 2020. Available: https://www.childrenscommiss ioner.gov.uk/report/inpatient-mental-health-wards-during-covid-19/

$28 \mathrm{RCPCH}$. Role of Paediatricians in supporting children and young people's mental health-position statement, 2020. Available: https:// www.rcpch.ac.uk/resources/role-paediatricians-supporting-childrenyoung-peoples-mental-health-position-statement

29 Wharff EA, Ginnis KM, Ross AM. Family-Based crisis intervention with suicidal adolescents in the emergency room: a pilot study. Soc Work 2012;57:133-43.

30 Evans ME, Boothroyd RA, Armstrong MI, et al. An experimental study of the effectiveness of intensive in-home crisis services for children and their families. J Emot Behav Disord 2003;11:92-102.

31 Lloyd-Evans B, Slade M, Jagielska D, et al. Residential alternatives to acute psychiatric hospital admission: systematic review. $\mathrm{Br} J$ Psychiatry 2009;195:109-17.

32 RCPCH. Paediatrics 2040 - a vision for the future of paediatrics in the UK from the Royal College of paediatrics and child health focusing on four areas- data, innovation, models of care and working lives, 2021. Available: file://C:/Users/jerem/Downloads/ Paediatrics-2040-Executive-Summary-Report-RCPCH-Feb-2021. pdf

$33 \mathrm{RCPCH}$. Paediatrician of the future: delivering really good training, 2020. Available: https://www.rcpch.ac.uk/resources/paediatricianfuture-delivering-really-good-training

34 Bulwer CE, Conn R, Cryer J. Thinking together: a pilot scheme linking paediatric and CAMHS trainees to improve collaboration and address training gaps. Archives of Disease in Childhood 2017;102. 